\title{
An experience with the Council of International Fellowship
}

\author{
Cathie Withington
}

Cathie Withington has 25 years social work experience, for voluntary, health and statutory agencies. She has a Diploma in Social and Community Work from Otago University. She achieved competency and registration in 2008, and is currently employed a s a social worker at Presbyterian Support Family Works in Ashburton.

It was an article in an ANZASW publication that first told me about Council of International Fellowship (CIF) programmes. The CIF is a private, voluntary, non-profit organisation founded in Germany in 1960. CIF consists of National Branches in many countries including New Zealand.

A typical exchange programme includes orientation, providing a theoretical framework to the social, economic and cultural trends in the country. Participants, who come from many different countries, make presentations about their work, as well as the socio-economic situation and cultural trends of their own country. This facilitates cultural exchange and sharing of ideas and skills.

Participants are placed in agencies related to their own field, to observe social work in the host country. As well, living with host families provides participants with a unique cultural experience that enriches understanding and tolerance and develops lasting friendships.

I was excited to imagine that I could travel to another country to learn about social work. The opportunity to learn from social workers from other parts of the world was also attractive. With wonderful support from my manager, I applied to attend programmes in Norway, Switzerland and Scotland. Norway said 'yes', Switzerland said 'maybe' and Scotland said 'no'.

Because I have a friend in Norway I decided to travel early so I could spend time with her before the programme started. My friend took me out and about and I was fascinated to see the traditional food-storage houses that the Norwegians have; so remarkably similar to a Maori pataka.

Almost as soon as I arrived, the eruption of the Eyjafjallajökull volcano in Iceland created an ash cloud that led to the closure of most of Europe's airspace, meaning people were unable to travel. I stayed with the Norway president of CIF for the first weekend of the programme, before moving to stay with my host-family, an office manager and a social worker with two teenage daughters. I enjoyed meeting a previous participant from Estonia who had returned to Norway to complete her masters degree in social work.

On Monday morning I travelled on Oslo's metro system to University College - Hogskolen I Oslo (HiO). This is comparable to our polytech. The complex was once three buildings next to each other. These have been covered in and connected by way of walkways and 
corridors. That evening I attended the committee meeting of the Norwegian CIF committee, two-thirds of whom are retired.

The decision to cancel the programme was the only one that could have been made; if they had continued with the programme they would have been morally responsible for the care and feeding of the participants if we had been trapped in Norway by ongoing eruptions. But it did leave me stranded.

My hosts did what they could to cobble together an indiviualised programme for me. I attended some lectures with the Masters in Social Work class, which were either in English or in Norwegian with someone sitting next to me translating. I spent Tuesday with one of the committee members. We talked for an hour or so about social work education in Norway and NZ then had lunch and went to the Nobel Peace Centre.

Next day I met with a social work student who is also a mentor for an ethnic minority child and we discussed the implications of mentoring minority children. I spent some time with an English-language copy of the Norwegian child protection legislation, looking at the differences between NZ and Norway. On Thursday I spent time preparing for my presentation on social work in NZ and on New Zealand's Family Group Conference system.

Friday morning I gave my first presentation wearing bare feet and a korowai. After a brief break, during which I changed into my regular clothes, I began my presentation on Family Group Conference. Within a short time the fire alarm sounded. With the sound of 'A fire has been detected. Please make your way immediately to the nearest exit. Do not use the elevators' ringing in my ears in Norwegian and English, I trudged down seven flights of stairs. Thank goodness I'd changed! It would have been most uncomfortable to stand outside for the best part of half an hour in six degrees, wearing little more than a cloak of fake kiwi feathers and bare feet. Luckily it was a false alarm.

Following the all clear I completed my talk then attended a lecture by Emad Al-Rozzi, an Occupational Therapist and actor who was born in a refugee settlement in Gaza, where his family has lived since 1948 . He came to Norway to complete his masters programme in special needs education in 2007. He was then unable to return home as the borders were closed. He had such a matter-of-fact way of accepting the hand he's been dealt - his family has been in a refugee camp for generations, he is unable to return home and he was 'filling in his time' (his words) by studying and lecturing.

Emad worked in Gaza with a team working with traumatised children. He told us of children traumatised by battles in their neighbourhoods, even their homes. Sometimes they take refuge in their school, only to have it bombed with white phosphorus, which burns on exposure to the air, and continues to burn for many minutes. When there has been a major incident, he and his team would go to the school the following day and present an opportunity for the children to talk and act out their experiences and feelings in a large group exercise. They also offered more in-depth therapy for longer-term, individual situations. I made contact with this man after the Greendale earthquake in September, and he responded immediately with some ways to help children here to deal with the trauma. 
That weekend there was a farewell party in my honour. I gave my presentation again, about myself and my work and about the NZ experience of FGC. There were dozens of questions and I enjoyed the experience of telling these interested and well-informed people about life and work in New Zealand.

During the second week I attended a workshop session on Mandala, a useful concept that I have utilised since my return. A second, enjoyable and valuable workshop the following day was on making and giving masks. It was a fun and interesting exercise and I anticipate using the technique and skills learned, with family, colleagues and clients.

I talked with a lawyer about the Child Welfare Act and its application in Norway. I was also privileged to visit a Women's Crisis Centre (Women's Refuge). The centre was on the site of a former old people's home; a surprisingly good use of the facilities. Each ward had been converted to a family room with its own en suite bathroom and there was a shared large sitting room and kitchen, a fenced play area outside and a laundry area.

In Norway, if you have nowhere to go, you will be sent to a hotel and the community must pay; a Women's Crisis Centre is for women who are threatened and mistreated, and their children.

I deeply regret that, because of the volcano and consequent cancellation of the programme, I was unable to experience the learning I'd anticipated. Although I would be accepted on the programme next year, it's too far and too costly to consider. What I did experience was based at the university and so the focus was on lectures rather than visits to actual workplaces to talk to the people who do the work.

On my last day I visited the Salvation Army, where we met the woman in charge of social work for the whole of Norway. A most prestigious and flattering visit. However, what I'd actually expressed an interest in was a visit to a local Salvation Army Centre, to see what they did, and how!

Landing in Christchurch, in spite of my exhaustion, was wonderful. I was delayed at one of the checkpoints because I had declared something for Agriculture and Fisheries to check - and then when I opened my bags, found I'd posted it! Apparently it is quite rare for people to declare something they do NOT have! 